\title{
WPEYW SENSORA Z WŁÓKIEN WĘGLOWYCH DO POMIARU ODKSZTAŁCEŃ NA NOŚNOŚĆ BELEK ŻELBETOWYCH
}

\begin{abstract}
Przyklejane do konstrukcji kompozyty zbrojone włóknem węglowym zdobywają coraz większą popularność w zastosowaniach budowlanych, jednakże, z uwagi na kruche właściwości ich użytkowanie jest obarczone znacznie większym ryzykiem niż w przypadku tradycyjnych stali. Diagnostyka wzmocnionych elementów tylko przez obserwację ich zarysowań czy ugięć może być niewystarczająca, potrzebne są dodatkowe systemy monitorujące. W referacie przedstawiono opracowaną przez autorów inteligentną tkaninę, w której wiązki włókien węglowych łączą rolę rozciąganego zbrojenia i miernika odkształceń. Zasada jej pracy jest inspirowana budową klasycznego tensometru elektrooporowego, którego włókna przewodzące prowadzone są wężykowo. Rolę przewodnika pełni wiązka włókien węglowych, która jest izolowana w matrycy $\mathrm{z}$ włókien szklanych lub akrylowych. Opisane w referacie wybrane wyniki badań laboratoryjnych są bardzo obiecujące zarówno w zakresie jakości pomiaru odkształceń, jak i efektywności wzmocnienia. Obecnie dopracowywane są: dokładność kontroli grubości wiązki włókien, która wpływa na całkowitą oporność, czy też wpływ wilgoci na zmiany oporności.
\end{abstract}

Słowa kluczowe: inteligentna tkanina, monitoring konstrukcji, pomiar odkształceń, laminat CFRP

\section{Wstęp}

Idea pomiaru odkształcenia poprzez rejestrację zmian oporności materiału ma długą historię, której kamieniem milowym jest opracowanie przez Edwarda Simmonsa i Arthura Ruge w 1938 roku i wprowadzenie do produkcji współcześnie niezwykle popularnych tensometrów elektrooporowych [6]. Tensometry zazwyczaj są naklejane na powierzchnię badanego materiału, lub na etapie pro-

\footnotetext{
${ }^{1}$ Autor do korespondencji/corresponding author: Rafał Krzywoń, Politechnika Śląska, Wydział Budownictwa, Akademicka 5, 44-100 Gliwice, +48 32 2372262, rafal.krzywon@ polsl.pl

${ }^{2}$ Marcin Górski, Politechnika Śląska, marcin.gorski@ polsl.pl

${ }^{3}$ Szymon Dawczyński, Politechnika Śląska, szymon.dawczyński@polsl.pl
} 
dukcji umieszczane wewnątrz (np. tensometry na zbrojeniu). Szczególnie w drugim przypadku wprowadzenie pomiarów może być bardzo utrudnione, zwłaszcza jeśli dotyczy konstrukcji istniejących, gdzie nie ma możliwości umieszczenia tensometrów w jej wnętrzu. Rozwiązanie tych niedogodności dają badania nad konstrukcjami o właściwościach samo-monitorujących. Przykładem mogą być badania nad zmianami oporności zbrojenia, które niestety nie znalazły zastosowań praktycznych z uwagi niewielką czułość. Współcześnie można zaobserwować powrót do idei pomiaru przez przewodność. Rozwijane są równoległe dwie konkurencyjne koncepcje - pomiaru przez zmianę przewodności światła $[2,4]$ i zmianę przewodnictwa elektrycznego [1].

Wprowadzenie do budownictwa laminatów zbrojonych włóknami wysokiej wytrzymałości daje nowe możliwości pomiaru odkształceń. Niektóre ze stosowanych włókien, oprócz bardzo dobrych właściwości wytrzymałościowych, cechuje dobra przewodność elektryczna. Najlepszym przykładem są włókna węglowe, po raz pierwszy praktycznie zastosowane w budownictwie w 1991 roku [3]. Dzięki wyśmienitym właściwościom mechanicznym (duża wytrzymałość na rozciąganie, wysoki moduł sprężystości) oraz fizycznym (niewielki stosunek ciężaru do objętości), są one aktualnie najpopularniejszym materiałem wykorzystywanym do wzmacniania konstrukcji budowlanych. Włókna węglowe niestety nie są pozbawione wad, z których bodaj najpoważniejszą jest niebezpieczeństwo kruchego zniszczenia. W konstrukcjach wzmacnianych, czy zbrojonych kompozytami FRP trudno z tego powodu liczyć na nadmierne ugięcie, czy zarysowanie mogące ostrzec użytkownika przed zagrożeniem. Wobec tej perspektywy wskazane jest szukanie innych metod określania zagrożeń.

Auto-monitoring wykorzystujący zmianę oporności elektrycznej jest jednym z możliwych rozwiązań. Badania nad monitoringiem z wykorzystaniem oporności laminatów można znaleźć w wielu dziedzinach techniki, gdzie włókna są stosowane znacznie dłużej niż w budownictwie [7]. Obejmują one jednak w przewadze sytuacje, w których zmiany przewodnictwa elektrycznego towarzyszą już fazie rozpoczynającej się destrukcji samego laminatu, co w przypadku konstrukcji budowlanych może nie zapewniać niezbędnego marginesu czasu potrzebnego np. na ewakuację.

\section{Rozwój koncepcji inteligentnej tkaniny}

Pomysł budowy laminatu zbrojonego tkaniną o właściwościach monitorujących rozwinął się na bazie niezwykle obecnie popularnych w przemyśle tekstylnym, inteligentnych ubrań. Pierwsze badania zmian oporności pojedynczych wiązek włókien okazały się niepowodzeniem. Towarzyszące wydłużeniom zmiany oporności znajdowały się poza zakresem czułości stosowanego mostka pomiarowego. Dopiero zwielokrotnienie długości włókien poprzez ich wężykowe ułożenie (na wzór tensometru oporowego) przyniosło oczekiwane efekty. 
Pierwsze próbne badania prowadzono na cienkich płytach z ręcznie ułożonym i laminowanym wątkiem włókien [5].

Ręczne układanie wiązki włókien z zachowaniem ich stałej długości i niewielkiego dystansu w zastosowaniach praktycznych byłoby niezwykle uciążliwe. Rozwiązanie tego problemu przyniosła współpraca nawiązana z pracownikami Wydziału Nauki i Technologii Tekstylnych Universidade da Beria Interior w Portugalii. Zastosowanie prostej techniki krosna czółenkowego, w którym osnową są naprzemiennie ułożone wiązki włókien węglowych i izolujących je włókien akrylowych, zaś wątkiem stabilizującym tkaninę są włókna bawełniane. Dodatkowo podwojono wiązkę włókien, a oporność jest mierzona poprzez podłączenie końców dwóch niezależnych wiązek. Na całkowity opór elektryczny równolegle ułożonej pary wiązek składa się suma oporu objętościowego włókien oraz oporu kontaktowego na styku obu wiązek. Zwiększenie oporności umożliwiło zwiększenie czułości rozwiązania. Wadą, związaną głównie z niestabilnością oporności kontaktowej, jest zauważalna zmiana oporności tkaniny występująca w trakcie laminacji i po wyschnięciu kleju. Pomimo obaw, nie zaobserwowano natomiast pogorszenia dokładności pomiarów, zwłaszcza liniowego przebiegu zależności odkształcenie - zmiana rezystancji, związanego ze zwiększeniem oporności kontaktowej w wyniku powstania mikropęknięć w silnie odkształconym laminacie.

Ostatecznie wykorzystany w opisywanych badaniach prototyp sensora tekstylnego wykonano $\mathrm{z}$ dwóch równoległych wiązek o właściwościach zawierających po 24 tys. włókien węglowych o gęstości $1,81 \mathrm{~g} / \mathrm{cm} 3$, przedzielonych wiązką włókien akrylowych o gęstości $1,17 \mathrm{~g} / \mathrm{cm} 3$ połączonych prostopadłym wątkiem włókien bawełnianych o gęstości $1,54 \mathrm{~g} / \mathrm{cm} 3$. Pozostałe właściwości tkaniny zestawiono w Tabeli 1 .

Tabela 1. Właściwości sensora tekstylnego, na podstawie [5]

Table 1. Properties of textile sensor, based on [5]

\begin{tabular}{|c|c|c|c|c|c|c|}
\hline $\begin{array}{c}\text { Liczba } \\
\text { włókien } \\
\text { wątku }\end{array}$ & $\begin{array}{c}\text { Gęstość } \\
\text { liniowa } \\
\text { wątku } \\
{[\mathrm{g} / \mathrm{m}]}\end{array}$ & $\begin{array}{c}\text { Wytrzy- } \\
\text { małość na } \\
\text { rozciąga- } \\
\text { nie [MPa] }\end{array}$ & $\begin{array}{c}\text { Moduł } \\
\text { sprężysto- } \\
\text { ści [GPa] }\end{array}$ & $\begin{array}{c}\text { Odkształ- } \\
\text { cenie przy } \\
\text { zerwaniu } \\
{[\%]}\end{array}$ & $\begin{array}{c}\text { Srednica } \\
\text { włókna } \\
{[\mu \mathrm{m}]}\end{array}$ & $\begin{array}{c}\text { Oporność } \\
\text { pojedyn- } \\
\text { czego } \\
\text { włókna } \\
{[\mu \Omega \mathrm{m}]}\end{array}$ \\
\hline 24000 & 1,6 & 5000 & 270 & 1,9 & 7 & 14 \\
\hline
\end{tabular}

\section{Opis procedury testowej}

Badania prowadzone w Laboratorium Politechniki Śląskiej dotyczyły zagadnień dokładności pomiaru oraz efektywności zbrojenia. W sumie objęły one grupę pięciu belek żelbetowych w skali rzeczywistej, z których dwie były wyposażone w sensor tekstylny. Ich cechy zebrano w Tablicy 2. 
Tabela 2. Porównanie cech badanych belek

Table 2. Properties of tested beams

\begin{tabular}{|c|c|c|c|}
\hline Oznaczenie & Wzmocnienie & Sensor tekstylny & $\begin{array}{c}\text { Nośność } \\
\text { (forma zniszczenia) }\end{array}$ \\
\hline \multicolumn{4}{|c|}{ Pierwsza seria badań } \\
\hline $\begin{array}{c}\text { BW } \\
\text { (belka referencyjna) }\end{array}$ & \multirow[b]{2}{*}{ brak } & brak & $47,3 \mathrm{kNm}$ \\
\hline $\begin{array}{c}\text { BST } \\
\text { (belka z naklejonym } \\
\text { sensorem tekstylnym) }\end{array}$ & & $\begin{array}{c}\text { przyklejony do } \\
\text { betonu wzdłuż } \\
\text { dolnej powierzchni }\end{array}$ & $\begin{array}{c}49,9 \mathrm{kNm} \\
\text { (zakotwienie) }\end{array}$ \\
\hline $\begin{array}{c}\text { BCFRP } \\
\text { (belka wzmocniona 2 } \\
\text { warstwami maty CFRP) }\end{array}$ & $\begin{array}{c}2 \text { warstwy maty } \\
\text { CFRP na odcinku } \\
\text { stałego momentu }\end{array}$ & brak & $\begin{array}{c}49,7 \mathrm{kNm} \\
\text { (zakotwienie) }\end{array}$ \\
\hline \multicolumn{4}{|c|}{ Druga seria badań } \\
\hline $\begin{array}{c}\text { BST_SRP } \\
\text { (belka wzmocniona 2 } \\
\text { warstwami taśmy SRP } \\
\text { oraz naklejonym senso- } \\
\text { rem tekstylnym) }\end{array}$ & \multirow{2}{*}{$\begin{array}{l}2 \text { warstwy taśmy } \\
\text { SRP } 3 \times 2-12 \text { szer. } \\
150 \mathrm{~mm} \text { wzdłuż } \\
\text { całej długości }\end{array}$} & $\begin{array}{l}\text { przyklejony do } \\
\text { powierzchni ta- } \\
\text { śmy SRP }\end{array}$ & $\begin{array}{c}104,9 \mathrm{kNm} \\
\text { (delaminacja + ze- } \\
\text { rwanie sensora) }\end{array}$ \\
\hline $\begin{array}{c}\text { BSRP } \\
\text { (belka wzmocniona } 2 \\
\text { warstwami taśmy SRP) }\end{array}$ & & brak & $\begin{array}{c}96,2 \mathrm{kNm} \\
\text { (delaminacja) }\end{array}$ \\
\hline
\end{tabular}

Badane belki miały wymiary przekroju $300 \times 200 \mathrm{~mm}$ (Rys. 1). Belki były zbrojone dołem 3 prętami \#12, górą dwoma prętami \# 8 i strzemionami \#6 co $150 \mathrm{~mm}$ ze stali stal B500SP. W badaniach oznaczono następujące właściwości betonu: $\mathrm{f}_{\mathrm{c}, \text { cube }}=44,7 \mathrm{MPa} ; \mathrm{f}_{\mathrm{ct}}=3,20 \mathrm{MPa} ; \mathrm{E}_{\mathrm{cm}}=30,1 \mathrm{GPa}$ Sensor tekstylny o szerokości około $120 \mathrm{~mm}$ i długości $1000 \mathrm{~mm}$ naklejano do dolnej powierzchni belki. W analogiczny sposób naklejono matę CFRP w belce BCFRP. Belki drugiej serii były wzmocnione 2 warstwami taśmy Hardwire SRP wzdłuż dolnej powierzchni, oraz przez owinięcie w strefie podporowej.

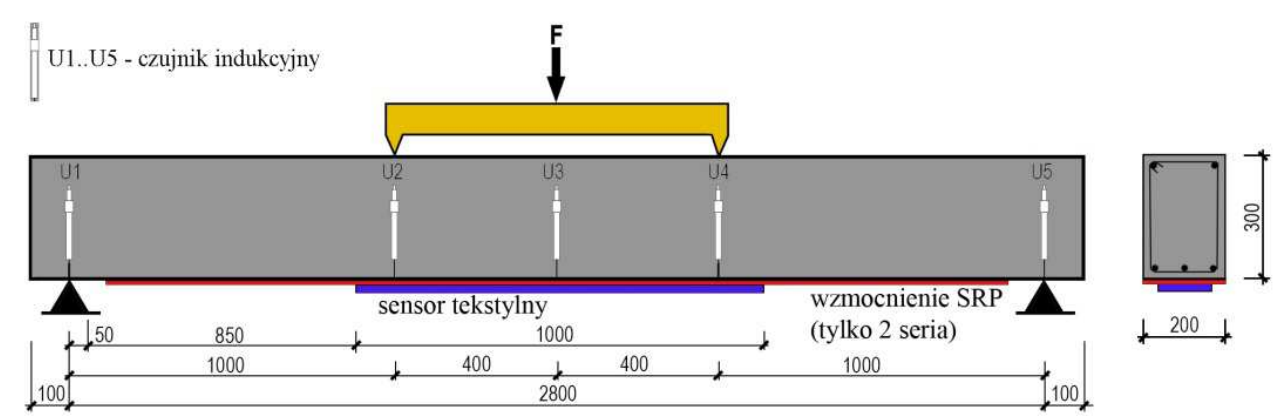

Rys. 1. Schemat belki na stanowisku badawczym wraz z opomiarowaniem

Fig. 1. Outline of tested beam with measuring 
Belki obciążano monotonicznie, aż do zniszczenia. Na rysunku 1 pokazano schemat przyjętego opomiarowania belek. Teoretycznie możliwy przyrost nośności po zastosowaniu tensora wynosi maksymalnie $23,6 \mathrm{kNm}$.

\section{Pomiary zmian oporności}

Zależność pomiędzy względną zmianą oporu elektrycznego a odkształceniem określa tzw. stała tensometru. Jej wartość oznacza się zazwyczaj doświadczalnie, tak też postąpiono w opisywanych badaniach. Wzdłuż całej długości sensora tekstylnego naklejono 9 tensometrów papierowych o bazie $75 \mathrm{~mm}$. Pomimo zamocowania sensora tekstylnego w strefie teoretycznie stałych momentów zginających, wskazania skrajnych tensometrów okazały się nieco mniejsze niż środkowych, co można łączyć z wpływem ciężaru własnego i odkształceń postaciowych zmieniających obraz krzywizny, dlatego stałą tensometru obliczono przez dopasowanie uśrednionego wskazania wszystkich 9 tensometrów elektrooporowych.

Wyniki pomiarów odkształceń dla obu grup badanych belek pokazano na wykresach (Rys. 2). Otrzymane wyniki badania zmian oporności należy uznać za bardzo obiecujące. Błąd pomiaru nie przekracza 5\%. Poprawny jest przebieg krzywych, wyraźnie dają się zauważyć załamania towarzyszące zarysowaniu belki oraz uplastycznieniu zbrojenia zwykłego. Większe różnice dla odkształceń przekraczających $4 \%$ o. Należy jednak podkreślić, że dla tych odkształceń rozpoczął się już proces niszczenia włókien sensora, ostatecznie zakończony jego całkowitym zerwaniem (Rys. 5).
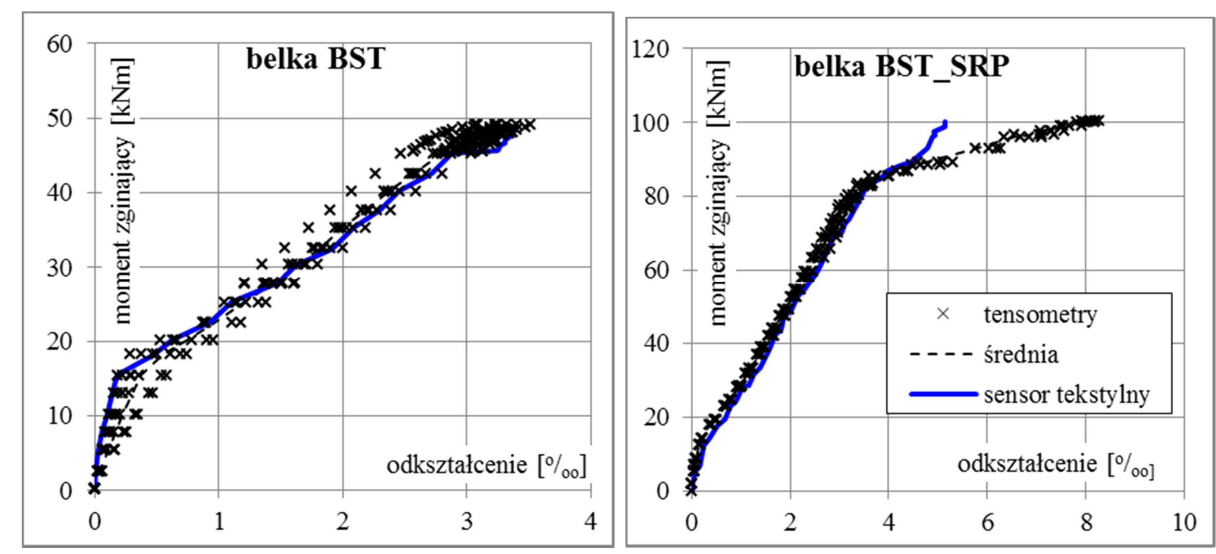

Rys. 2. Porównanie wskazań tensometrów elektrooporowych i sensora tekstylnego na wykresach zależności moment zginający - odkształcenie (opis w tekście)

Fig. 2. Comparison of strain gauges and textile sensor measures un the graphs showing bending moment - strain dependence (description inside text) 


\section{Wpływ sensora na nośność przekroju}

Założenie wstępne pomiaru odkształceń wyłącznie na odcinku stałego momentu zginającego okazało się nieco niefortunnym rozwiązaniem z punktu widzenia badań efektywności wzmocnienia. Kotwienie laminatu w strefie maksymalnych momentów zginających doprowadziło do szybkiej delaminacji końców wraz z fragmentem otuliny. Zachodziła ona wkrótce po przyspieszeniu przyrostu odkształceń strefy rozciąganej związanym z uplastycznieniem zbrojenia. Zarówno forma zniszczenia, jak i wartość odkształceń przy których ono nastąpiło są jednakowe dla belki wzmocnionej sensorem tekstylnym i porównawczej, wzmocnionej dwoma warstwami maty CFRP (Rys. 3, Rys.4).
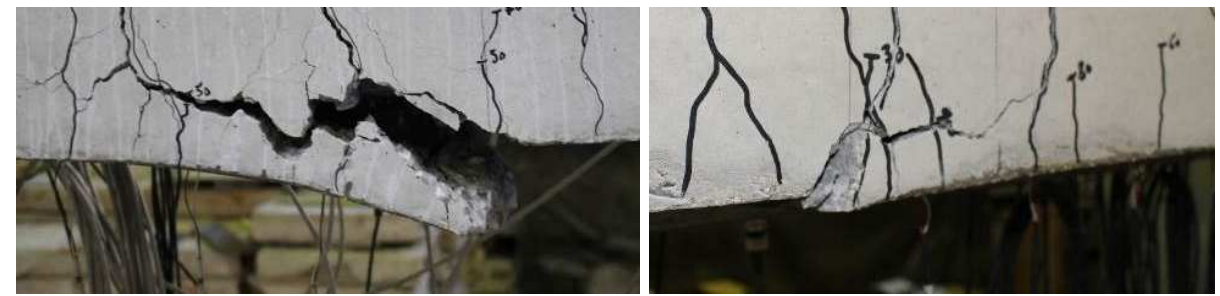

Rys. 3. Forma zniszczenia belek pierwszej serii badań (z lewej belka z naklejonym sensorem tekstylnym, z prawej belka wzmocniona matą CFRP)

Fig. 3. Form of destruction of beams in the first series (on the left beam with textile sensor, on the right strengthened by CFRP sheet)
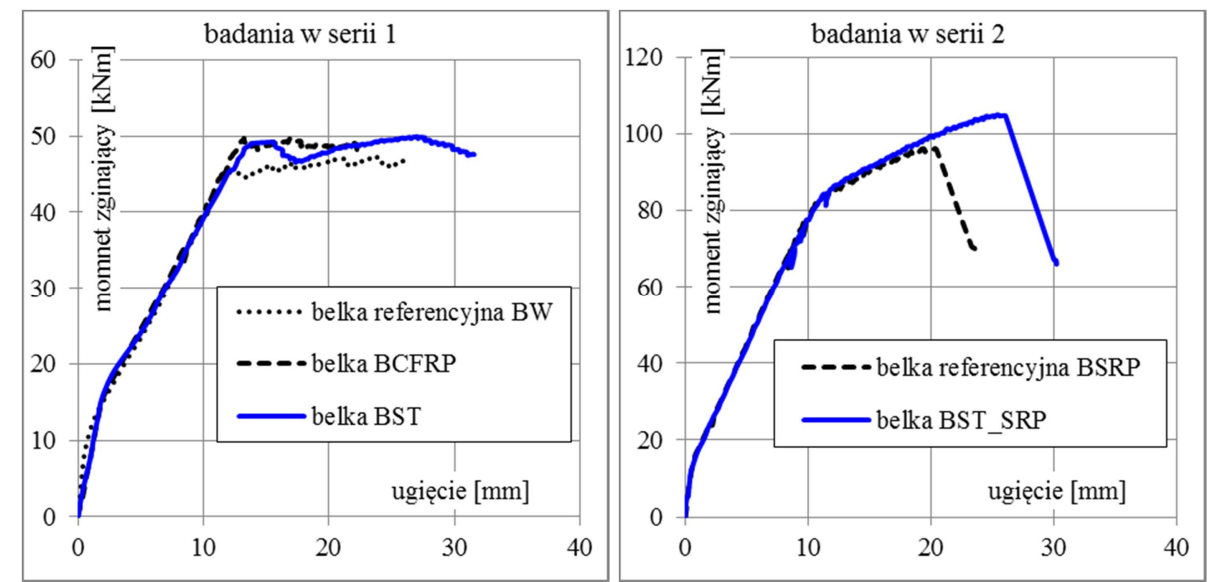

Rys. 4. Porównanie skuteczności wzmocnienia na wykresach zależności moment zginający ugięcie (opis w tekście)

Fig. 4. Comparison of strengthening efficiency in the graphs showing bending moment - deflection dependence (description inside text) 
Zdecydowanie lepsze wyniki, potwierdzające potencjał wzmacniający opracowanej inteligentnej tkaniny uzyskano w drugiej serii badań, gdzie sensor tekstylny został naklejony na laminat zbrojony włóknami SRP jako druga (dodatkowa) warstwa zewnętrznego wzmocnienia. Takie rozwiązanie pozwoliło wyeliminować problem lokalnej koncentracji naprężeń związanej z zakotwieniem końca sensora. Otrzymany w badaniu efekt w postaci skuteczności wzmocnienia przerósł pierwotne oczekiwania. Nośność na zginanie wzrosła o ponad $9 \mathrm{kNm}$ co stanowi prawie $10 \%$ wzrost w stosunku do belki wzmocnionej wyłącznie laminatem SRP. Wynik tego badania pokazano na rysunku 4. Widoczny na nim jest nie tylko opisany przyrost nośności, ale również nieznaczne ograniczenie ugięć, zwłaszcza po uplastycznieniu zbrojenia zwykłego. Skuteczności, z jaką sensor tekstylny został wciągnięty do współpracy w przenoszeniu obciążeń dowodzi również jego forma zniszczenia przez zerwanie włókien (Rys. 5), niezwykle rzadko obserwowana w przypadku laminatów CFRP.
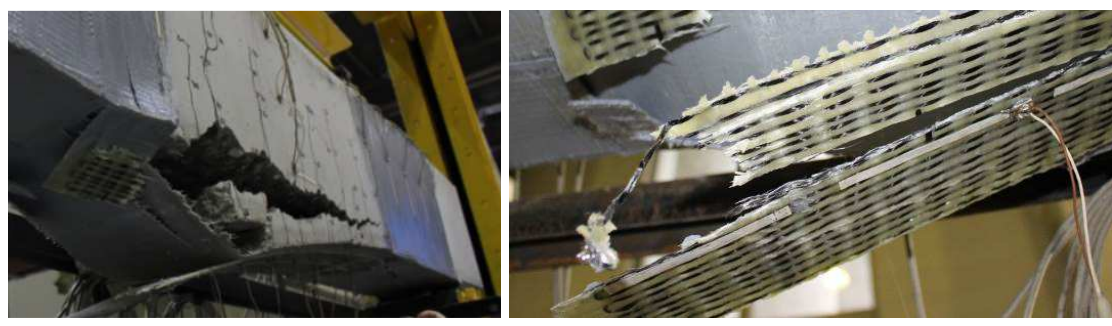

Rys. 5. Zerwanie włókien węglowych sensora tekstylnego w zniszczonej belce

Fig. 5. Carbon fibers rupture of textile sensor in the damaged beam

\section{Podsumowanie}

Przedstawiona koncepcja pomiaru odkształceń przez zmianę oporności laminatu zbrojonego włóknem węglowym nadal pozostaje w fazie badań. Już na tym ich etapie można jednak zauważyć duży potencjał rozwiązania, zarówno jako wzmocnienia konstrukcji, jak i sensora odkształceń. Oczywiście uzyskiwana dokładność pomiarów odbiega od możliwości klasycznych tensometrów elektrooporowych, jednakże przewidywanym zastosowaniem produktu nie jest poszerzenie bazy laboratoryjnych urządzeń pomiarowych, a raczej zastosowanie praktyczne, uwarunkowane licznymi współczynnikami bezpieczeństwa, które również mogą obejmować dokładność samych wskazań.

Do najpoważniejszych wad opisanego sensora, wymagających dalszego dopracowania należą dość prymitywna forma produkcji (użycie ręcznego krosna czółenkowego), dość wyraźna zmiana oporności tkaniny przed i po laminacji oraz zauważalna wrażliwość na wilgotność otoczenia. Zagadnienia te są aktualnie w fazie badań doświadczalnych, pozwalających na ich lepsze rozpoznanie i ewentualnie eliminację. 
Opisane badania zostały w części sfinansowane przez Komisję Europejską w projekcie nr 251373 (FP7-PEOPLE-2009-IAPP)—INSYSM.

\title{
Literatura
}

[1] Chen P.W., Chung, D. D. L., 1993. Carbon fiber reinforced concrete for smart structures capable of non-destructive flaw detection. Smart Materials and Structures, vol. 2, no. 1, s. 22-30.

[2] Kenel, A., Nellen, P., Frank, A., Marti, P., 2005. Reinforcing Steel Strains Measured by Bragg Grating Sensors. J. Mater. Civ. Eng., 4(423), s. 423-431.

[3] Meier, U., 1995. Strengthening of structures using carbon fibre/epoxy composites. Construction and Building Materials, Vol. 9, No. 6, Elsevier Science, Great Britain.

[4] Merzbacher, C. I., Kersey, A. D., Friebele, E. J., 1996. Fiber optic sensors in concrete structures: a review. Smart Materials and Structures, vol. 5, no. 2, s. 196-208.

[5] Salvado, R., Lopes, C., Szojda, L., Araújo, P., Gorski, M., Velez, F.J.; CastroGomes, J., Krzywon, R., 2015. Carbon Fiber Epoxy Composites for Both Strengthening and Health Monitoring of Structures. Sensors, 15.

[6] Stein P.K., 2001. Strain Gage history and the end of the twentieth century Experimental Techniques Vol. 25, Issue 2., s. 15-16.

[7] Wang X., Chung D.D.L., 1996. Continuous carbon fibre epoxy-matrix composite as a sensor of its own strain. Smart Materials Structures 5. S. 796-800.

\section{INFLUENCE OF CARBON FIBRE STRAIN SENSOR ON BEARING CAPACITY OF RC BEAMS}

\begin{abstract}
S u m m a r y
Externally bonded high-strength fiber composites are increasingly popular in structural applications, however, because of their brittle properties, their use is less secure than the common steel. Diagnosis this type of structure only by observing of cracks or deformations may be insufficient, they require additional monitoring systems. Paper presents developed by the authors' intelligent fabric, wherein the carbon fiber tow links the role of tensile reinforcement and strain gauge. Its way of working is inspired by the construction of traditional strain gauge, where electric wires are arranged in zig-zag pattern. Carbon fiber thread plays the role of electrical conductor and is insulated by threads of glass or acrylic fibers. Described in the paper selected results of laboratory trials are very promising in both the accuracy of strain measurement, and the effectiveness of strengthening. Among the issues for improvement is the control of the cross-section of the fibers tow, affecting the total resistance of the fabric and moisture sensitivity.
\end{abstract}

Keywords: smart textile, structure monitoring, strain measures, CFRP laminate

Przestano do redakcji: 07.06.2016 $r$.

Przyjęto do druku: 30.06.2016 $r$.

DOI: $10.7862 / r b .2016 .31$ 